\title{
Las políticas de vivienda social en Chile en un contexto de neoliberalismo híbrido
}

Xenia Fuster-Farfán. Universidad de París 8, Centre de Recherche sur l'Habitat, París, Francia.

RESUMEN | La revisión de las políticas habitacionales vigentes en Chile permite analizar el neoliberalismo híbrido en tanto paradigma de intervención social. Su hibridez radica en el ensamblaje entre elementos del neoliberalismo, con propuestas de inversión y promoción social. Se sostiene que esta hibridez, en el caso chileno, se expresa en la mantención del sistema subsidiario, la tercerización de la intervención, la realización de proyectos que buscan ser más pertinentes a las realidades culturales y territoriales y, paradójicamente, el aumento del protagonismo del aparato público. Se busca demostrar, mediante el análisis cualitativo de cuatro conjuntos habitacionales, que los elementos mencionados pueden dar origen a "casos excepcionales" en la política de vivienda social, con un incremento en la calidad de la oferta que no logra constituirse en el estándar para toda la población atendida. Se concluye que la política pública así definida produce nuevas brechas en la calidad de los bienes y servicios que provee.

PALABRAS CLAVE | política habitacional, gestión territorial, desigualdad social.

ABSTRACT | In the framework of social policy paradigms, specifically within the framework of housing policies, the concept of hybrid neoliberalism is proposed to understand a new paradigm of social intervention. The hybrid approach in social intervention lies in the connection between elements of neoliberalism with proposals for investment and social promotion. The article argues that this hybridization, in the Chilean case, takes place in the enduring subsidiary system, the outsourcing of the intervention, the execution of projects that seek to be more relevant to cultural and territorial realities, and paradoxically, in the increasing prominence of the public system. The aim is to demonstrate through the qualitative analysis of four housing complexes, that the aforementioned elements can give grounds for "exceptional cases" in social housing policy, with an increase in the quality of the housing supply that does not reach the requested standards of the entire served population. The paper concludes that public policy produces new gaps, which in this case, translate in a differentiated experience in the quality of the goods and services provided.

KEYWORDS | housing policy, territorial management, social inequality.

Recibido el 19 de marzo de 2018, aprobado el 17 de julio de 2018.

E-mail: xenia.fuster@gmail.com 


\section{Introducción: los paradigmas en la política de vivienda social}

Las políticas de vivienda social en Chile han sido analizadas desde perspectivas históricas y jurídicas, también según sus propuestas arquitectónicas y urbanas, y a partir del rol y percepción de quienes las habitan, de sus apuestas políticas, entre otros enfoques. Para abordar este conjunto de líneas temáticas, se ha desarrollado un sinnúmero de trabajos provenientes de la academia, la sociedad civil, el sector privado y el mismo sector público. A modo de no reiterar estos esfuerzos, existe un consenso en la presencia de al menos tres grandes paradigmas contemporáneos en las políticas sociales chilenas y, por consecuencia, en las de vivienda. Estos son: el keynesianismo o apogeo del Estado de Bienestar; el neoliberalismo "fundacional" que sigue, en la medida de lo posible, la pureza de la propuesta neoliberal; y el neoliberalismo híbrido, basado en estrategias de intervención de promoción e inversión social y empresarial.

\section{El Estado de Bienestar: la vivienda para la clase trabajadora}

Tras la crisis económica liberal de 1929, del laissez-faire y el apogeo de la cuestión social, nuevos paradigmas comenzaron a definir la relación entre el Estado y las personas. El modelo económico dominante en esa época, fundado en la teoría keynesiana y los modos de producción fordista, supuso, de una parte, la asistencia y apoyo por parte del aparato estatal a quienes presentaban necesidades y riesgos generados por la sociedad mercantil; y de otra, la promoción y fortalecimiento de organizaciones sindicales. Se puede, entonces, afirmar que estos componentes del Estado de Bienestar "limitan y mitigan el conflicto de clases, equilibran la asimétrica relación de poder entre trabajo y capital, y de ese modo ayudan a superar la situación de luchas paralizantes y contradicciones que constituía el rasgo más ostensible del capitalismo liberal" (Offe, 1990, pp. 135-136). Vale decir, en un contexto de posguerra, este Estado permite dar solución política a ciertas contradicciones económicas y sociales. Así, el Estado se posiciona como administrador de la vida política, económica y social y, por consecuencia, se robustece mediante la construcción de un aparato jurídico-técnico interno, desplegando una red de protección social amplia en las dimensiones de educación, salud, vivienda, trabajo y previsiones. En este sentido, nos enfrentamos a un modelo protector y solidario, que tiene como características principales la promoción de la seguridad, beneficios y servicios sociales, la universalización de la cobertura, la participación estratégica de la asistencia social y la prevención de riesgos e incertidumbres futuros (Pereira, 2004).

Pinson y Reigner (2012) complementan esta lectura destacando el avatar territorial del Estado keynesiano, para lo cual acuñan la noción de keynesianismo espacial, donde se implementan políticas de redistribución espacial de la riqueza y en el cual "la estandarización es un patrón de las políticas públicas en general, y de las políticas urbanas y de planificación del territorio en particular" (p. 168). En relación con las acciones en materia de vivienda en Chile, entre los ańos treinta y cuarenta el arriendo era la principal forma de acceso a la vivienda, por lo que el Estado, a través de distintos organismos, fomentó una intervención que regulaba los arriendos, protegía a la población de las especulaciones y promovía la creación 
de cooperativas de vivienda, a la vez que comenzó a construir alojamiento para la población más necesitada (Hidalgo, 1999). Sin embargo, los conflictos entre arrendatarios y propietarios se agudizaron, así como las dificultades de la población para acceder a un terreno o vivienda propios. Por esta razón es que, llegados los años cincuenta, surgieron las primeras tomas de terreno (Espinoza, 1988; Garcés, 2002) y las primeras experiencias de producción masiva de vivienda en las periferias de las ciudades producidas por la Corporación de Vivienda (Corvi) (Hidalgo, 2005). Con ello se dio comienzo al periodo más importante del movimiento de pobladores chileno, el cual fue apoyado por las fuerzas políticas de izquierda, que buscaban instituir los principios del Estado de Bienestar.

En el país, las últimas políticas de vivienda social basadas en el enfoque protector y solidario datan del año 1970, bajo el gobierno de Salvador Allende, donde la vivienda era considerada como un derecho cuyo reparto no se podía regir por las reglas de la economía, sino por las necesidades y condiciones sociales (Hidalgo, 1999). En este sentido, el rol del Estado se volvió aún más activo: "entre sus principios, se planteaba la necesidad que fuera el propietario del suelo y el encargado de construir y controlar la edificación de acuerdo con las exigencias urbanísticas y sociales, las cuales debían primar por sobre el carácter especulativo" (Hidalgo, 2002, pp. 224-225). Estos nuevos fundamentos provocaron molestia en los grupos empresariales del sector de la construcción, a la vez que alentaron el fortalecimiento del movimiento de trabajadores y pobladores ante los procesos de estatización de dichas empresas. Fue así que las medidas adoptadas tanto en el campo de la vivienda como en otras áreas de la política social, y la reacción y presiones de aquellos sectores que se veían afectados por el modelo socialista, comenzaron a generar diversas crisis políticas. Fue el poder de esos sectores, junto con el apoyo directo de Estados Unidos, desencadenaron una crisis económica y social, dando pie a la ocupación militar del Estado el 11 de septiembre de 1973.

\section{El neoliberalismo fundacional: la vivienda como estrategia política}

La crisis del modelo protector y solidario comenzó a visibilizarse, produciéndose un renacimiento intelectual y político del neo-laissez faire y de doctrinas económicas monetaristas (Offe, 1990). En Chile (en el contexto de la dictadura militar) y en el mundo, durante los años ochenta y noventa se desplegó el "giro neoliberal". Este tipo de políticas se basa en un referencial de mercado (desregulado y sostenido en la austeridad presupuestaria) y se centra en financiar y sostener la oferta, dejando en un segundo lugar las aspiraciones, requerimientos y particularidades de la demanda (los habitantes y/o población objetivo de la política pública) (Ravinet \& Palier, 2015). De hecho, se puede sostener que el neoliberalismo es un tipo de gubernamentalidad (Dardot \& Laval, 2010; Foucault, 1976-1988) no solo del mercado y de la política, sino también de los individuos.

Esta nueva recomposición no se sostenía ya sobre una política general y universal de reducción de desigualdades, ni en una política de integración inspirada en un ideal de igualdad, como era la aspiración del paradigma bienestarista. Al contrario, se imponía una tendencia que se alejaba progresivamente del ideal igualitario y de integración, institucionalizando una política llamada "activa", que operaba en 
reacción a la lógica liberal o ultraliberal (Hamzaoui, 2002). Es decir, el paradigma cambió de un ideal de igualdad a un principio de individualización de lo social que demandaba cada vez más seguridad. Sumado a esto, el Estado neoliberal, en el contexto latinoamericano, comenzó a destacar por la reducción de derechos al mínimo y el aumento de la participación del mercado; se privatizaban los servicios públicos y tercerizaba su prestación, y se enfatizaba una política monetaria y el ajuste fiscal para favorecer el flujo del capital financiero (De Paula Faleiros, 2004). De este modo, las políticas de corte universal fueron consideradas como poco racionales desde el punto de vista económico, por lo que se hizo necesario impulsar políticas focalizadas en la población más necesitada.

En el ámbito de la vivienda, el año 1993 el Banco Mundial propuso a los Estados desplazarse desde su rol activo al de facilitador: "Se aconseja a los gobiernos que dejen de lado su anterior función de productores de viviendas y que asuman el papel de facilitadores de su administración en la totalidad del sector. Este cambio fundamental es necesario si se quiere dar a los problemas de vivienda una solución proporcional a su magnitud -el mejoramiento sustancial de las condiciones de vivienda de los pobres-y si se quiere administrar el sector de la vivienda como sector económico importante” (p.1). Su propuesta (que Chile asumió prácticamente en plenitud) supone que el "problema de la vivienda de los más pobres" es un asunto que el mercado puede resolver. Rolnik (2017) sugiere que el buen funcionamiento de este sistema contribuiría a objetivos financieros más amplios, como, por ejemplo, la posibilidad de movilizar el capital o realizar ajustes fiscales, todo "en la medida que los gastos públicos se dieran a través de subsidios más transparentes y focalizados, y pudieran movilizar los capitales privados" (p. 68).

Las políticas de vivienda en Chile no quedaron ajenas a este modelo, y bajo la justificación de la necesidad de disminuir el déficit habitacional, se creó y consolidó un sistema subsidiario y tercerizado al mundo privado: se trataba de entregar vouchers transables en el mercado por una vivienda propia. En definitiva, una reacomodación de clases según la cual se transformaba a los "proletarios en propietarios" (Borja, 2015). Este proceso fue acompańado por una suerte de urbanidad neoliberal, proceso que contempló la privatización y liberalización de los mercados urbanos por medio de la "eliminación de normas sobre límites urbanos, eliminación de impuestos y regulaciones a mercados inmobiliarios, venta de suelo urbano en manos del Estado; entre otras" (Sabatini, 2000, p. 4). Según el mismo Sabatini, tres principios definían los lineamientos de dichas políticas: uno, el suelo es declarado un recurso no escaso; dos, el mercado es responsable de la asignación de tierras en sus distintos usos, ya sea público o privado; y finalmente, tres, el mercado es un ente regulador del uso del suelo a partir de disposiciones flexibles que eliminan las restricciones de crecimiento urbano. En este contexto, la localización, características y calidad de las soluciones habitacionales dependen de la relación dialéctica entre presupuesto y precio (Hidalgo, Paulsen \& Santana, 2016).

Después de un acuerdo político con el régimen militar en 1989, la “izquierda chilena” (la Concertación de Partidos por la Democracia) ostentó el poder durante veinte años. Si bien en los años noventa el déficit habitacional se vio palpablemente disminuido, comenzaron a surgir problemas que hasta fechas recientes seguían 
siendo desatendidos. De hecho, hace más de diez años salió a la luz uno de los libros más importantes para el mundo académico-político vinculado a la vivienda en Chile (posiblemente hasta el día de hoy, a pesar de las importantes distancias temporales): Los con techo. En aquel libro, Rodríguez y Sugranyes (2005) describen el principal problema de la política neoliberal: "con el transcurso de los años, la meta cuantitativa se convirtió en criterio de excelencia del ministro de Vivienda de turno, y ahí el criterio mercantil y el criterio político coincidieron: mejor ministro quien hace más casas; la calidad, la localización, el entorno, no otorgan puntaje en el escenario político" (p. 15). Es decir, la producción masiva sin cálculo social dominaba el esquema de las políticas sociales de vivienda. De hecho, en el mismo período se consolidó el modelo ABC (Ahorro, Bono, Crédito) para aumentar el valor pagado por las viviendas, haciendo que fueran más atractivas para las inversiones privadas. De este modo, se consolidó una nueva identidad en la clase política: la nueva izquierda neoliberal.

Para hacer justicia a la historia, en este período podemos identificar dos momentos del neoliberalismo: uno experimental (hasta el año 1989), y uno corregido (Garretón, 2012), que en algunas áreas profundiza el carácter neoliberal, mientras en otras el Estado intenta asumir un rol de regulador o participante (Maillet, 2015).

\section{El neoliberalismo híbrido: la vivienda individualizada y territorializada}

La noción de neoliberalismo híbrido surge en el contexto de la pax neoliberal (Gaudichaud, 2015), donde las tradicionales fuerzas políticas chilenas (la derecha, el centro y la izquierda) acuerdan que es este el modelo que se debe seguir. La noción de hibridez refiere a una de las características principales del neoliberalismo: su plasticidad, su capacidad de adaptarse a los distintos contextos (Brenner \& Theodore, 2005) y de combinar variables; y, en consecuencia, su indefinición. Tal como lo señalan Brandsen, Van de Donk y Putters (2005) al cualificar al tercer sector, la hibridez se caracteriza por su condición camaleónica; "el camaleón se caracteriza por su estrategia de cambiar de color, por lo que las organizaciones híbridas podrían clasificarse por sus estrategias, por sus métodos de adaptación a las demandas [que están] en conflicto" (p. 760). Vale decir, es una condición que permite adaptarse a contextos y demandas cada vez más complejos.

Es un período en que se profundizaban las reformas estructurales posdictadura, se impulsaron políticas sociales de protección social hiperfocalizadas, se identificó aquella población sobre la cual debía intervenirse prioritariamente (es el caso de pueblos originarios, mujeres, adultos mayores, niños y niñas, personas en situación de discapacidad, ${ }^{1}$ entre otras), y se reafirmó y racionalizó el sistema subsidiario para asegurar la adecuada participación de los tres actores fundamentales en la política pública (y particularmente en la de vivienda): habitantes, Estado y mercado.

A fines de los ańos noventa comenzaron a emerger (o más bien se develaron pública y masivamente) las primeras problemáticas asociadas a las políticas de

1 Producto de ello es que en Chile se crean instituciones especializadas para trabajar con este tipo de población. Es el caso de la Corporación de Desarrollo Indígena (Conadi), el Servicio Nacional de la Mujer (Sernam), el Servicio Nacional de Adulto Mayor (Senama), el Servicio Nacional de Menores (Sename), el Servicio Nacional de Discapacidad (Senadis), entre otros. 
vivienda social implementadas en dictadura. Tal como se indicó anteriormente, se comenzó a hablar de los problemas de los "con techo", vale decir, aquellas situaciones vividas por aquellos que ya habían tenido acceso a la vivienda. Los autores lo ilustran así: "el problema de los 'con techo'. Es decir, la solución dada al problema de los 'sin techo' -la producción masiva de vivienda social- ha llevado a una situación de insatisfacción de sus beneficiarios respecto a la materialidad y diseño de las viviendas y su entorno; y particularmente respecto de las condiciones de convivencia familiar y social que en ellas se dan, y de su marginación de la ciudad. El stock construido hoy día es un problema habitacional, pero también social" (Rodríguez \& Sugranyes, 2005, p. 17). Expresiones claras de esta descripción son los casos de las conocidas “casas Copeva", "viviendas nylon”, la expoblación "Las Viñitas" en Cerro Navia, Bajos de Mena en Puente Alto, entre muchas otras. Adicionalmente, podemos afirmar que este periodo es testigo del resurgimiento del movimiento de pobladores representado no solo por la condición de clase, sino de otras categorías que este modelo crea: las familias allegadas, las deudoras habitacionales, indígenas urbanos (Fuster, 2015; Imilan, 2017a), los con techo, damnificados, entre otros.

El año 2006, la discusión en torno a los temas de vivienda se desplazó hacia las cuestiones del hábitat y la ciudad. Es por ello que en el mismo período se creó un programa que marca un punto de inflexión respecto a todos los paradigmas dominantes: el Programa de Regeneración de Barrios (Quiero Mi Barrio). Si bien este tipo de programas ya existía en otros países, en Chile introdujo abiertamente el desafío de desplazar la discusión desde el déficit cuantitativo al déficit cualitativo. En él se propone, como uno de los componentes más importantes, las metodologías de corte participativo, de modo de involucrar y vincular a los vecinos con las soluciones espaciales del Programa. Esta tendencia o "vuelco hacia los habitantes" se expresa también en las políticas de vivienda social, que incorporan en su normativa la implementación de Planes de Habilitación Social que acompañan este proceso, el aumento en los montos de los subsidios, una mayor calidad de la vivienda y espacios públicos, la mejora en la localización, la creación de indicaciones y definición de situaciones especiales en el sistema de subsidio "regular" (que podrían considerarse acciones de políticas de discriminación positiva o affirmative action), entre otras, que permiten vislumbrar la existencia de un nuevo paradigma en las políticas de vivienda social: si bien mantiene las lógicas subsidiarias, utiliza estrategias de promoción social para otorgar mayor pertinencia contextual a sus soluciones.

Un ejemplo de lo mencionado anteriormente es que, en los últimos dos decretos que reglamentan el Fondo Solidario de Vivienda (que, en resumidas cuentas, es el programa de vivienda destinado a la población vulnerable), el Decreto Supremo $\mathrm{N}^{\circ}$ 174 y el $\mathrm{N}^{\circ} 49,{ }^{2}$ se otorgan puntajes adicionales a familias que cuenten con integrantes entre 0 y 5 años, entre 6 y 18 años, con más de 60 años; integrantes voluntarios del cuerpo de bomberos; integrantes que hayan realizado el servicio militar; integrantes que sean funcionarios de Gendarmería, e integrantes que posean y Además, este último modifica el título del programa, de Fondo Solidario de Vivienda a Fondo Solidario de Elección de Vivienda, instalando la lógica según la cual la vivienda social es parte de la oferta del mercado. 
demuestren condiciones "especiales" de vulnerabilidad: personas en situación de discapacidad; personas reconocidas como víctimas en el informe de la Comisión Nacional sobre Prisión Política y Tortura; y madres o padres solteros, divorciados o viudos que tengan a su cargo personas menores a 24 ańos. A su vez, las personas en situación de discapacidad, indígenas, adultos mayores de 60 años, las personas reconocidas como víctimas en el Informe de la Comisión Nacional sobre Prisión Política y Tortura, y las personas en condición de viudez, se encuentran exentas de acreditar núcleo familiar (requisito básico para la postulación "regular" a la vivienda). También existen incentivos para aumentar el monto de los subsidios a grupos familiares numerosos; a personas en situación de discapacidad (a quienes se les otorga entre 20 y 80 uf [us $\$ 880-3.523$ ] adicionales ${ }^{3}$ para la adecuación de sus viviendas); a los ahorros que superen el monto requerido; al emplazamiento, condición y localización del terreno, y a la tipología de las viviendas. Por último, se ha popularizado cada vez más por parte del Ministerio de Vivienda y sus servicios, los llamados a postulación especial para situaciones particulares, concebidos como una forma directa de atender la singularidad. Desde este punto de vista, estos nuevos tipos de políticas buscan luchar contra la exclusión y la vulnerabilidad social (que son producto del modelo capitalista), más que por cuestiones de desigualdades sociales. Vale decir, intentan corregir los "errores" o "desviaciones" del sistema, más que transformarlo estructuralmente. De hecho, observando durante años el funcionamiento de las agrupaciones que buscan vivienda (comités de vivienda), se puede afirmar que, con el perfeccionamiento normativo de los grupos vulnerables, se ha desarrollado una verdadera competencia en torno a demostrar "quién es más vulnerable o pobre", para aumentar la competitividad de un proyecto por sobre otro.

Es así que la problemática sobre la que centra su preocupación la política social se moviliza desde la injusticia y la desigualdad hacia una concepción liberal de equidad y discriminación positiva. De este modo, se funda una nueva doctrina de la cuestión social, la cual otorga una posibilidad de "redefinir los elementos constitutivos de una intervención pública sobre lo social, llamada política diferenciada y territorializada, cuya concepción general, sus principios y procesos son la individualización de lo social, la selectividad del público, de sus prestaciones y del territorio y, finalmente, la responsabilización de sus beneficiarios" (Hamzaoui, 2002, pp. 41-42).

Es relevante indicar que la búsqueda de pertinencia (individual y territorial) está lejos de ser universal (dentro de la población ya focalizada) y homogénea: dependerá de la capacidad de movilización de los recursos locales por parte de sus habitantes, el interés y prioridad política de actores privados y autoridades, y el contexto político, económico y social en el cual se desenvuelven. En este sentido, el propósito de este artículo es analizar este último periodo, el cual pretende instaurar un nuevo paradigma en las políticas de vivienda social mediante la implementación de acciones excepcionales: son de un mayor estándar y pertinencia contextual y cultural, pero eventualmente únicas y poco replicables. 


\section{Metodología}

Los resultados que se presentarán son producto de una investigación doctoral en curso que tiene como objetivo principal analizar este paradigma contemporáneo de las políticas de vivienda social en Chile. Su abordaje se realizó a través de un estudio de casos de conjuntos de vivienda social enmarcados en el Fondo Solidario de Vivienda, producidos y habitados en un rango de diez años (2006-2016), que coincide con el surgimiento del D.S. $\mathrm{N}^{\circ} 174 \mathrm{y}$ su posterior actualización en el D.S. $\mathrm{N}^{\circ}$ 49. Todos estos casos fueron especialmente seleccionados por su carácter excepcional.

La condición de excepcionalidad en el contexto de esta investigación es la presencia de uno o más actores asociados al caso no contemplados en la política regular, mayor inversión o complementariedad de recursos, difusión pública, su presentación como un proyecto "exitoso" o perteneciente al grupo de "buenas prácticas”, ${ }^{4}$ y la focalización en algún grupo prioritario para la política. Bajo esta perspectiva, se identificaron cuatro categorías que agrupan el origen de estos proyectos: el contexto de urgencia, la prioridad política otorgada al caso, la presión ejercida por sus habitantes o por el mercado, y la condición de grupo prioritario al cual se focaliza la política. Para los fines de este artículo, se presentará un caso por cada una de estas categorías.

En términos de técnicas de producción de información, se realizó un conjunto de entrevistas y conversaciones con habitantes, dirigentes y líderes, funcionarios municipales, del Servicio de Vivienda y Urbanización (Serviu) regional y del Ministerio de Vivienda y Urbanismo (Minvu), representantes de Entidades Patrocinantes (EP), autoridades, constructoras, arquitectos y fundaciones, en caso de corresponder. En total se realizaron cien entrevistas (hasta la fecha), entre semiestructuradas y abiertas, que tuvieron por objetivo identificar aquellos elementos que dieron origen a la excepcionalidad del caso, los instrumentos, presupuestos, negociaciones, conflictos y actores presentes, la expresión espacial/territorial de la excepcionalidad, y las prácticas y percepciones de los casos una vez habitados. Esta información primaria fue posteriormente complementada con análisis de prensa, de documentos, bases de datos y observación directa en cada caso.

\section{Algunos casos "excepcionales"}

En el presente apartado se realizará una descripción analítica de cuatro de los casos abordados, que representan las categorías antes mencionadas: contexto de urgencia, prioridad política, presión social y condición de grupo prioritario.

En el caso del contexto de urgencia, se analizarán las viviendas palafito de la localidad de Dichato en la comuna de Tomé, región del Biobío. Como iniciativa de proyectos para compartir”, producidos entre los años 2006 y 2009. El año 2017 se publicó otro catálogo de similares características, pero que destaca aquellas obras urbanas y habitacionales con pertinencia indígena. Ambos documentos reflejan los esfuerzos del Ministerio por difundir proyectos destacados o innovadores. 
prioridad política, se trabajará con el caso San Francisco (conocido también como Neo Cité) en la comuna de Santiago, región Metropolitana. Como expresión de presión social, se encuentra el caso del conjunto Pacífico Rivas de la comuna de San Joaquín, región Metropolitana. Por último, por su condición de grupo prioritario, se analizarán las viviendas para población mapuche de la comuna de Huechuraba (conocida públicamente como las "viviendas ruka”), región Metropolitana.

\section{Dichato: "gracias a Dios y al presidente Piñera"}

El terremoto y tsunami del 27 de febrero de 2010 (27F) afectó a gran parte de la población nacional. Sin embargo, hubo territorios más afectados, especialmente los ubicados en el borde costero, donde el tsunami hizo desaparecer gran parte de las viviendas, comercio y equipamiento. La localidad de Dichato de la comuna de Tomé (región del Biobío) fue una de las más afectadas, pero también una de las más publicitadas por las autoridades y los medios de comunicación. En ese contexto, la reconstrucción de viviendas se ha abordado mediante dos mecanismos: construcción en nuevos terrenos a las afueras de Dichato (casas) y en el borde costero (edificios), y construcción en sitio propio (para propietarios de los terrenos) en el centro de la ciudad y en el borde costero (bajo la tipología de vivienda en palafito).

Las viviendas palafito en el borde costero de Dichato (sector de Villarrica) constituyen un conjunto compuesto por 17 casas, cuyo costo de construcción bordeó un total de 400 millones de pesos (us\$ 656.759) con una superficie de $52 \mathrm{~m}^{2}$. Cuentan con un primer piso libre e inundable ante un eventual tsunami, el cual puede ser utilizado como lugar de trabajo o bodega, mientras que el segundo piso se ubica a una altura que, para mayor seguridad, supera los dos metros (Ministerio de Vivienda y Urbanismo, 2013).

La innovación del proyecto radica en la posibilidad de permanencia de la comunidad cerca de su lugar de trabajo, asociado a la recolección de algas y la pesca. A su vez, el proyecto reconoce las características geográficas locales, mediante un diseño que favorece la reconstrucción temprana ante un eventual tsunami (Building and Social Housing Foundation, 2016). Es por ello que, el año 2016, estas viviendas fueron finalistas en los "premios mundiales del hábitat", concurso organizado por Building and Social Housing Foundation y ONU-Hábitat.

Las viviendas se concretaron por medio de la Normativa Técnica del Ministerio de Vivienda y Urbanismo 007, denominada "Diseńo estructural para edificaciones en áreas de riesgo de inundación por tsunami o seiche" (Minvu, 2013), la que se dictó con la finalidad de autorizar la construcción de viviendas en zonas inundables, permitiendo la producción de casas con materiales resistentes al mar. Debido a que la ingeniería de las viviendas suponía costos adicionales a los que el Minvu desembolsa regularmente, los subsidios de reconstrucción fueron complementados con el "subsidio de mitigación", que permitió a cada familia contar con cerca de 150 uF (us\$ 5.682) por sobre las proyectadas.

Tal como se mencionó anteriormente, la premisa de construir estas viviendas en zonas inundables fue respetar la cultura local de sus habitantes; por tanto, primó la permanencia de estos en su territorio más que la expulsión. Ahora bien, poco fueron consideradas en el diseño las características particulares de sus ocupantes: la mayoría 
son adultos mayores, y muchos de ellos con dificultades de desplazamiento. Por estas razones es que en algunas viviendas se comenzó a construir y habilitar la zona planificada como inundable (el primer piso). Esto se puede observar en la figura 1.

FIGURA I | Viviendas palafitos originales e intervenidas

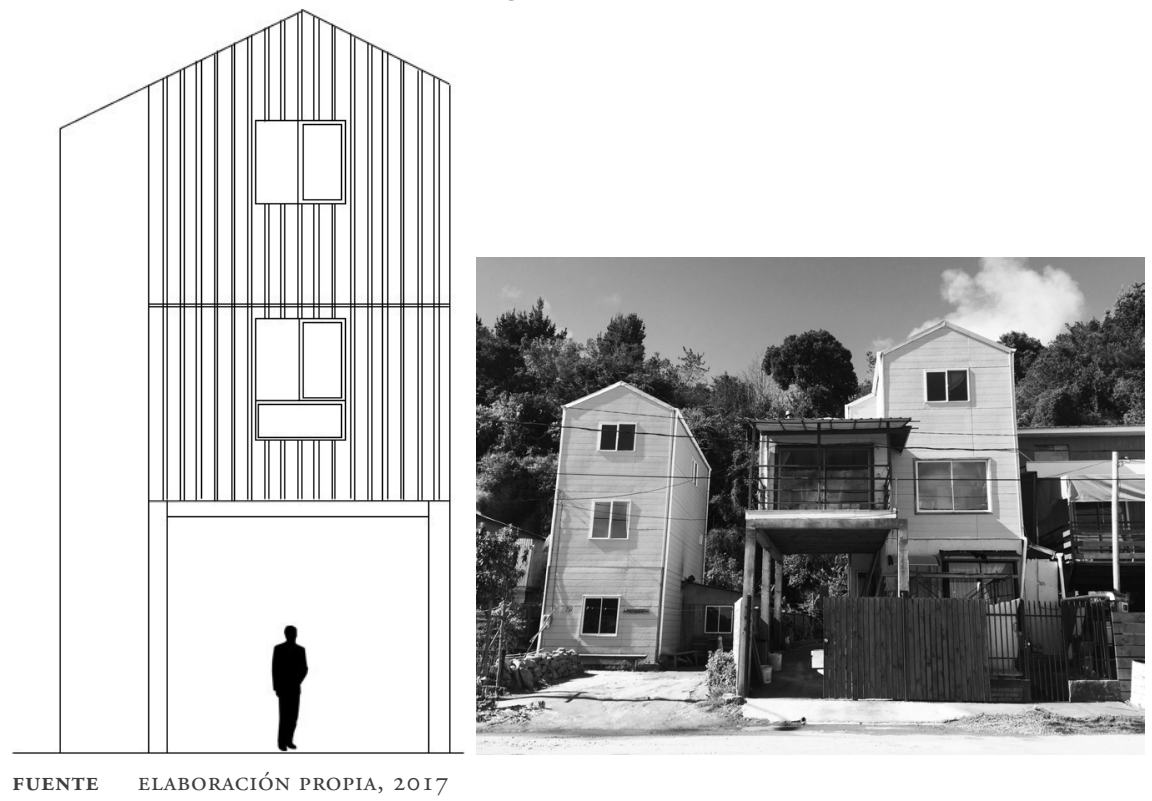

A pesar de las importantes y evidentes dificultades de accesibilidad, sus habitantes destacan el tamaño y alto estándar de la vivienda y, por sobre todo, la posibilidad de quedarse en sus terrenos (a diferencia de lo ocurrido en otros territorios de similares características, donde la población tuvo que desplazarse). Gloria, habitante de 80 ańos, recalca que la existencia de estas viviendas se debe principalmente a la gestión directa del Gobierno Central: "estamos aquí gracias a Dios y al presidente Piñera". Por su parte, Ramón, uno de los líderes en el proceso de reconstrucción de estas viviendas, explica que la localización y tipología se deben a la mediatización de Dichato pos-27F, a la organización y presión que ejercieron como habitantes y al involucramiento de distintos actores públicos, privados y del mundo de la academia en el proceso de reconstrucción de la localidad.

Esta información ha permitido reafirmar no solo la laxitud normativa y presupuestaria con la que se interviene en contextos de emergencia, sino también la forma en que este contexto desregulado se expone a la definición de urgencias políticas. En la figura 2 se puede observar la presencia del ministro de Vivienda y Urbanismo de la época en la inspección de estas viviendas (actividad inusual en un ministro, con la salvedad de que el caso sea considerado "especial"). 
FIgURA 2 Ministro de Vivienda en inspección de obras en Dichato

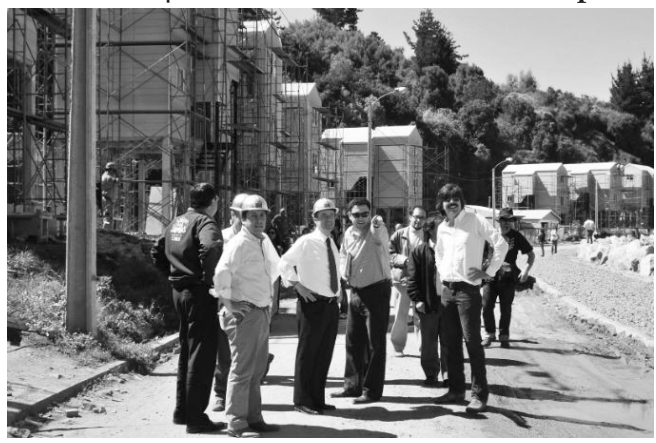

FUENTE MINISTERIO DE VIVIENDA Y URBANISMO, 20 I 2

Neo Cité: el Municipio como un actor relevante en la política de vivienda social El conjunto San Francisco (o Neo Cité, como es apodado por los distintos actores), comprende viviendas sociales del año 2014 que albergan a 48 familias que se encontraban en situación de allegados y arrendatarios en la comuna de Santiago.

Este proyecto fue implementado en un terreno de $1.352 \mathrm{~m}^{2}$ diseńado bajo la tipología de cité, compuesto por dos brazos de tres y cuatro pisos de departamentos dúplex, situados en paralelo, ubicados perpendicularmente a la calle, que se enfrentan por medio de un patio comunitario, donde las viviendas de 55 a $72 \mathrm{~m}^{2}$ (muy por sobre el estándar de la vivienda social "regular", de $42 \mathrm{~m}^{2}$ ) se orientan en dos direcciones, ya sea hacia el patio interior o a la calle (Franco, 2015). Se puede observar esta distribución en la figura 3.

FIgURA 3 Neo Cité, exterior e interior

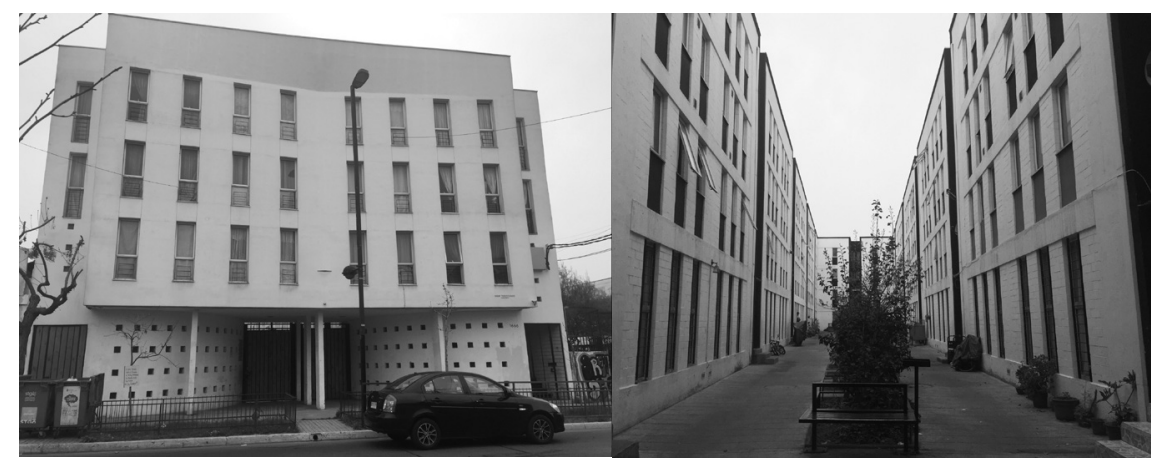

FUENTE ELABORACIÓN PROPIA, 2017

El Neo Cité es una propuesta piloto planteada por el arquitecto Iván Theoduloz en conjunto con la Ilustre Municipalidad de Santiago. En este sentido, tanto los habitantes como los funcionarios de la Gerencia Técnica de Vivienda de la Municipalidad indican que este proyecto surgió como iniciativa personal del 
exalcalde Raúl Alcaíno, ${ }^{5}$ y que luego fue retomado por las dos administraciones posteriores. Su objetivo fue resolver la demanda habitacional de los allegados pertenecientes a la comuna mediante la revitalización de un espacio patrimonial, al reconstruir la principal tipología arquitectónica tradicional barrial que posee la comuna de Santiago: el cité. Lo que define el carácter innovador del proyecto, y por el cual se le atribuye su singularidad, es que en la historia de la política de vivienda en Chile no existen proyectos de renovación urbana asociados a la tipología de cité.

El proyecto Neo Cité se encuentra ubicado en una zona de alta plusvalía en el centro de la ciudad (así se puede observar en la figura 4) y fue la primera oportunidad para desarrollar un proyecto de vivienda destinado a familias vulnerables. Sobre esto último, una funcionaria de la Gerencia Técnica de Vivienda del Municipio de Santiago señaló que, hasta la fecha, "estábamos erradicando a las familias pobres de la comuna a la periferia de Santiago”, aspecto que motivó aún más al Municipio a invertir en este proyecto. De hecho, el aporte municipal no operó solo mediante la inyección de recursos extras (donación del terreno y recursos complementarios), sino que también incluyó la selección de los beneficiarios, lo que supuso que la organización inicial de la demanda no tuvo su origen en los futuros residentes del conjunto (procedimiento que sí se realiza en contextos "regulares").

\section{FIgura 4 Vista aérea, Neo Cité}

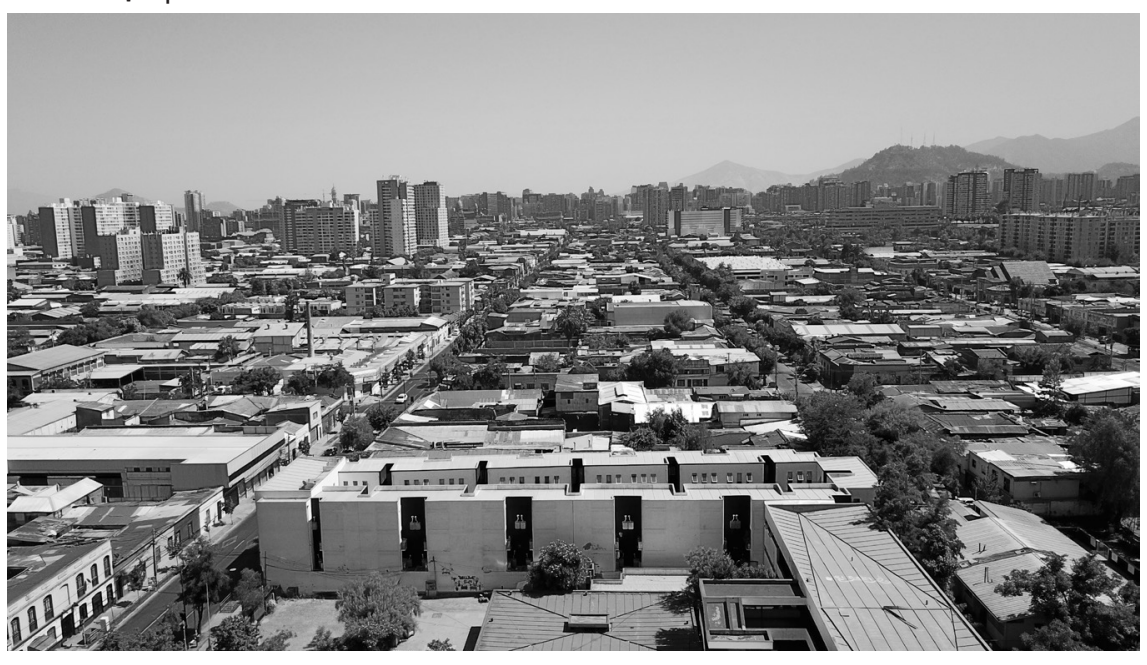

FUENTE ELABORACIÓN PROPIA, 20 I 8

En relación con lo anterior, es importante recalcar que en la política de vivienda "regular", los municipios no poseen ninguna participación activa, sino -en generalsolo administrativa (aprobación de las construcciones y recepción de las obras). En los últimos ańos, los municipios se han vinculado a la política bajo la figura de 
Entidad Patrocinante, espacio originalmente destinado a empresas, organizaciones o fundaciones. Sin embargo, esta participación depende de la voluntad de cada municipio; vale decir, no es un requerimiento obligatorio establecido por la política. Al respecto, en el período 2003-2018 solo el 3\% de las Entidades Patrocinantes corresponde a municipios (considerando solo proyectos de gran escala: construcción en nuevos terrenos, megaproyectos y densificación predial).

El conjunto fue construido en un terreno de propiedad municipal, y el costo aproximado de la obra se estimó en \$ 1.151.093.920, lo que equivale a 48.982 uF aproximadamente (US\$1.855.465), valor que fue financiado en un 68,65\% por aportes del Serviu; 30,1\% por la Municipalidad de Santiago; y el 1,25\% proveniente de los beneficiarios. Cabe mencionar que el aporte entregado por el Municipio se desglosa en 5.616 uf (US\$212.734) para la construcción y 9.600 uF (US\$ 363.648) destinadas al terreno (Franco, 2015).

Finalmente, es posible mencionar que el Neo Cité es considerado un caso exitoso en el mundo de la arquitectura, habiendo sido seleccionado el año 2015 por la XIx Bienal de Arquitectura de Chile y la xv Bienal Internacional de Arquitectura de Buenos Aires, Argentina, lo que ha favorecido su posicionamiento como una iniciativa replicable en otros barrios de Santiago y comunas de la Región Metropolitana.

Marta (45) y Carmen (74) coinciden en que la posibilidad de quedarse en la comuna y contar con departamentos de gran tamaño en comparación con sus anteriores viviendas (la mayoría de sus habitantes eran allegados o arrendaban en piezas dentro de grandes casonas antiguas de la comuna) las posiciona en una condición de "privilegio". De hecho, según el representante de la Entidad Patrocinante, "la gente iba a preguntar dónde estaba la sala de ventas", confundiendo este proyecto con uno dispuesto en el mercado inmobiliario. Sin embargo, y debido a que los habitantes fueron seleccionados por un ente externo (Municipalidad) y no por una organización propia, tanto los funcionarios y profesionales de la Entidad Patrocinante, como los mismos habitantes, declaran que los principales problemas del proyecto refieren a la convivencia vecinal. De hecho, María indicaba que las personas externas los llaman "La Legua chica". ${ }^{6}$

\section{Pacífico Rivas: la demanda de los allegados}

El condominio Pacífico Rivas 1 y 2 del año 2015 es un conjunto de viviendas sociales que acoge a doscientas familias allegadas de la comuna de San Joaquín. Por su condición de pericentro, San Joaquín ha experimentado un aumento en la plusvalía del suelo de 7,35 uf (US\$ 61) en 2008 a 17,3 uf (us\$ 768) el metro cuadrado en el periodo 2014-2017. . En la figura 5 se puede observar la localización de San Joaquín y de Pacífico Rivas en el límite con la comuna de Santiago centro.

6 La Legua es un barrio histórico de Santiago, reconocido -y estigmatizado- por la presencia de narcotráfico.

7 Cálculo realizado con base en la información de oferta de suelo 2014-2017 de San Joaquín (Ilustre Municipalidad de San Joaquín, 2017). 
FIGURA 5 Localización referencial de Pacífico Rivas en relación con el centro de Santiago

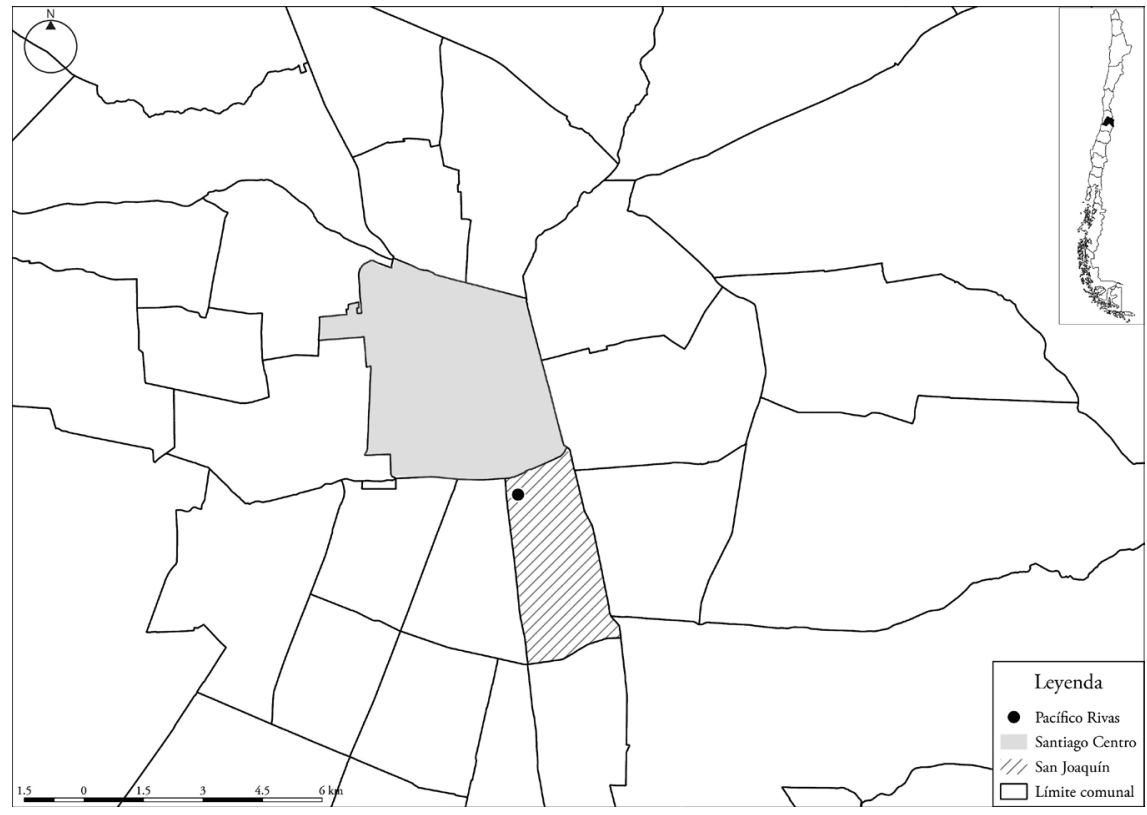

FUENTE ELABORACIÓN PROPIA, 2018

La obra está compuesta por diez condominios de cinco pisos con cuatro departamentos por cada piso, que suman un total de doscientos departamentos de $57 \mathrm{~m}^{2}$ que cuentan con tres dormitorios, un baño, logia y balcón. Además, disponen de sede social, sala de basura, juegos infantiles, estacionamientos, y un total de $519 \mathrm{~m}^{2}$ de áreas verdes (Ilustre Municipalidad de San Joaquín, 2013).

Una de las particularidades, tanto de este como de otros proyectos de la comuna, es el interés que ha mostrado el alcalde Sergio Echeverría ${ }^{8}$ por detener la expulsión de población pobre hacia las periferias de la ciudad. Para ello ha desarrollado iniciativas tendientes a reubicar a los residentes que desean obtener su casa propia en terrenos fiscales disponibles dentro de la misma comuna y, de esta manera, detener el desarrollo de los potenciales sectores concentradores de pobreza (mal llamados guetos), producto de las políticas de vivienda implementadas a partir de los ańos ochenta. De hecho, podemos observar cómo los municipios aledaños a San Joaquín han optado por promover el desarrollo inmobiliario (así se puede observar en la figura 6), mientras que la comuna ha optado por hacer que sus habitantes se mantengan en ella y no se desplacen a otras donde los estándares de localización son más bajos. Al igual que en el caso del Neo Cité, uno de los elementos destacables de Pacífico

Alcalde independiente apoyado por la coalición de centro-izquierda. Asumió la alcaldía el año 2008, y el año 2016 fue reelecto hasta el ańo 2020 con un 75,99\% de los votos. Habitantes y funcionarios destacan que su gestión ha estado enfocada en la vivienda, el medioambiente y el desarrollo urbano. 
Rivas es su ubicación en un terreno de alta plusvalía: cercano a avenidas principales conectoras, corredores de buses (Transantiago) y la reciente inauguración de una estación de Metro a tan solo 500 metros de distancia.

\section{FIgURA 6 | Vista aérea, Pacífico Rivas}

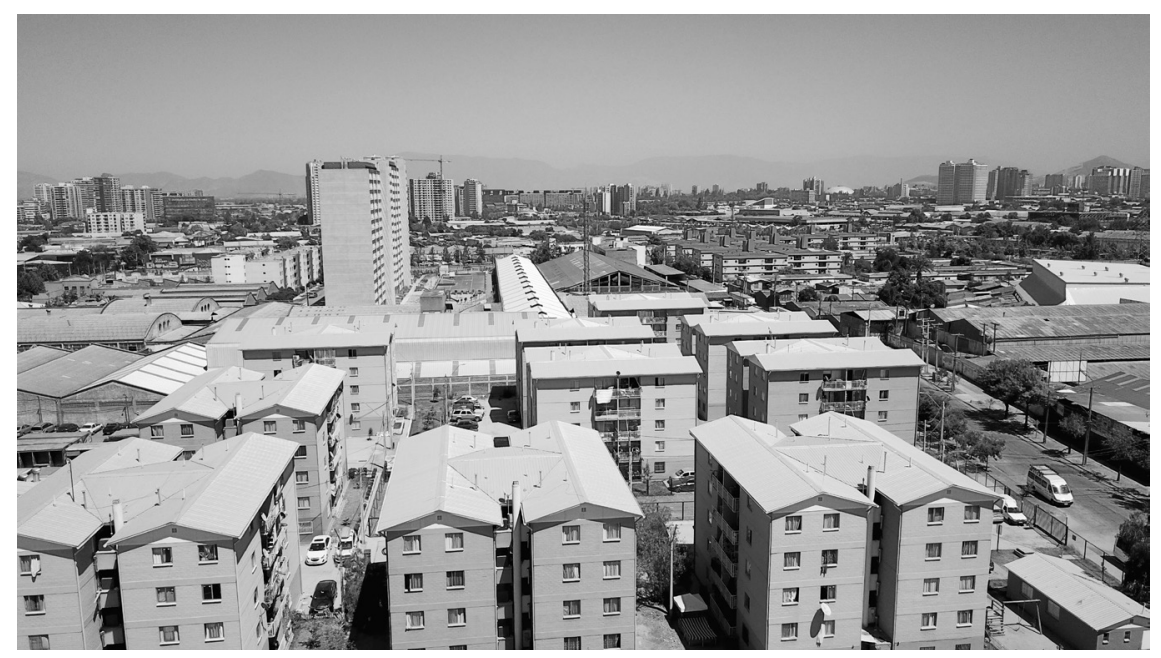

FUENTE ELABORACIÓN PROPIA, 2018

Los dirigentes actuales del condominio indican que la singularidad del proyecto es ser producto de la presión de las agrupaciones de allegados de la comuna, con el apoyo del Municipio: "el alcalde no habría conseguido estos terrenos si los dirigentes no ayudan a protestar y presionar al Minvu” (Sebastián, dirigente). Según destacan los habitantes y funcionarios municipales, Pacífico Rivas es un ícono, porque es el conjunto de vivienda social más grande de la comuna hasta el momento, y representa una victoria producto de cerca de ocho años de movilización de los allegados de San Joaquín.

Podemos observar que este es un ejemplo de las nuevas configuraciones del movimiento de pobladores, el cual, a diferencia del vigente en los años sesenta, que se movilizaba principalmente sobre la base de necesidades en un contexto profundo de pobreza urbana (Angelcos \& Pérez, 2017), hoy demanda derechos sociales. Uno de los dirigentes del conjunto observa claramente esta diferencia: "le dices a un poblador que va a vivir a un condominio, se vuelve vecino, no poblador. Pasar de poblador a copropietario es un mundo de distancia”.

\section{Viviendas ruka: "somos la envidia misma"}

Las viviendas ruka (del mapudungun 'casa') son un conjunto de viviendas sociales del año 2011, ubicadas en el sector La Pincoya de la comuna de Huechuraba, en el que residen 25 familias de la etnia mapuche que se encontraban en situación de allegadas y que estaban organizadas en la Asociación Mapuche de la comuna. Estas 
viviendas estuvieron a cargo del arquitecto responsable Cristián Undurraga (reconocido arquitecto nacional) y la constructora $\mathrm{EBCO}$, con la colaboración conjunta de la Ilustre Municipalidad de Huechuraba (según los entrevistados, la exalcaldesa Carolina Plaza ${ }^{9}$ fue fundamental para la concreción del conjunto), de la Fundación Techo para Chile y de la Corporación Nacional de Desarrollo Indígena. Si bien se puede afirmar la inexistencia de una política de vivienda indígena (Imilan, 2017b), las de este conjunto se acogen al programa Fondo Solidario de Vivienda, que incorpora consideraciones especiales para personas de origen étnico. Entre ellas, la posibilidad de postulación sin núcleo familiar, a diferencia de las personas no indígenas (Fuster \& Ayenao, 2016). De hecho, en una de las publicaciones más recientes del Minvu sobre pertenencia indígena, incorporan este y otros proyectos, indicando que se trata de "experiencias innovadoras que, en armonía con la cosmovisión, identidad y cultura de los pueblos indígenas, han buscado mejorar sustancialmente las condiciones de habitabilidad de esta población, tanto en el ámbito de la vivienda como en el barrio" (Saball, 2016, pp. 6-7).

Esta iniciativa formaba parte de un proyecto de mayor alcance, que contempló la edificación de 415 casas en el sector de La Pincoya, con el objetivo de resolver la necesidad habitacional de los campamentos Guerrillero y Esperanza y Fe. El costo total de este proyecto (dividido en dos etapas) fue de aproximadamente $\$ 6.000$ millones (Us\$ 9.949.412) (Blanco, 2010).

La particularidad de las viviendas ruka radica en ser el primer proyecto de viviendas sociales en territorio urbano que integra, según sus creadores, la cosmovisión de la etnia mapuche. La singularidad de las viviendas, de $61 \mathrm{~m}^{2}$ es la incorporación de los siguientes aspectos: ubicación a los pies del cerro y orientación horizontal de las viviendas, por la búsqueda de cercanía a la naturaleza; fachada principal en dirección al oriente, para que la puerta principal se abra hacia el sol naciente; técnica de construcción de ladrillo artesanal y marco de hormigón; diagonal de pino en las fachadas principal y posterior, como símbolo la conexión de la tierra con el universo; palos de coligüe en ambas fachadas ubicados de forma horizontal, lo que permite el paso de luz filtrada, evocando la penumbra de las rukas; separación de la cocina y el bańo (ubicados en el primer y segundo piso, correspondiente a ubicación en las viviendas sociales "tradicionales"); y diseño de las habitaciones de tal modo que el respaldo de la cama mire hacia el norte (Aravena, 2011; Portal Inmobiliario, 2011). Adicionalmente, para emplazar las viviendas según los requerimientos de sus habitantes, fue necesario remover una parte del cerro para posteriormente reforzarlo. Esto, según los entrevistados, significó un aumento sustancial en los costos de construcción, que tuvieron que ser complementados con recursos municipales y particulares (de parte de la constructora y de la oficina de arquitectura). En la figura 7 se puede apreciar su diseño exterior. 
FIGURA 7 Viviendas ruka desde el exterior

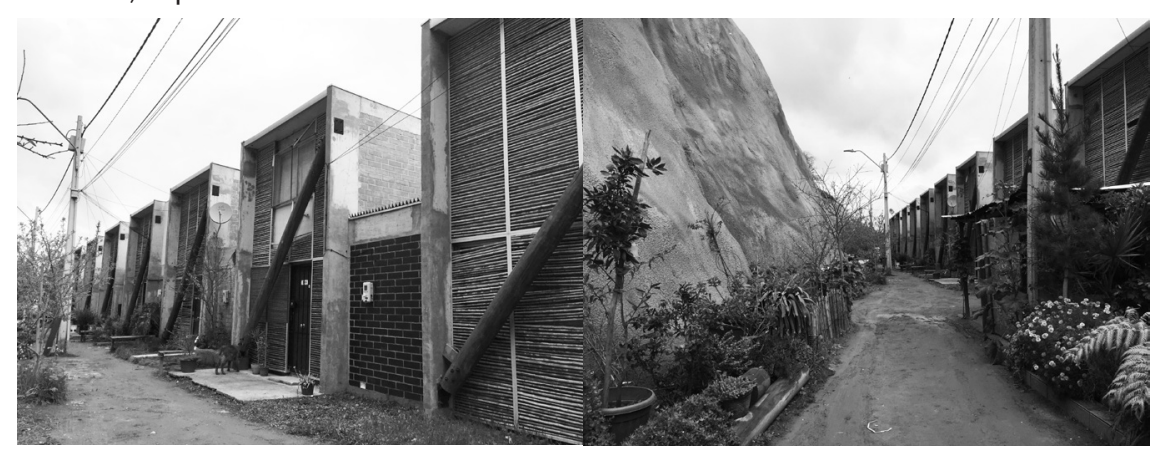

FUENTE ELABORACIÓN PROPIA, 2017

A pesar de que sus habitantes reconocen el esfuerzo del equipo por desarrollar una propuesta distinta de diseńo, indican que existen elementos fundamentales que no fueron tomados en cuenta, o que los resultados fueron reinterpretaciones. Entre los elementos no incorporados está el diseńo ovalado, la ubicación del baño y la materialidad de la ruka original, y entre los reinterpretados, el tronco que cruza el exterior de la vivienda (que debe estar al centro de ella) y la utilización de los coligües en la fachada (estos se pueden utilizar como parte del mobiliario o para la estructura del tejido). De hecho, la mayoría de sus habitantes indica que los coligües han desarrollado termitas, por lo que en muchas viviendas han tenido que retirarlos. Elena, una de sus habitantes, expresa que "los coligües son para las casas de los animales, no de los humanos". Por su parte, una de las dirigentas del conjunto señala que la negociación del diseño y localización de las viviendas fue extenso debido a las diferencias de expectativas y conocimientos sobre la cultura mapuche, pero sin embargo "para mí fue solo desconocimiento. Ahora somos la envidia misma".

\section{Conclusiones: una política que transita entre excepciones y diferenciaciones}

El año 2010, el Minvu dio una señal sobre su intervención excepcional y diferenciadora en la construcción de vivienda social, a través de la publicación de un catálogo que recoge 45 proyectos "destacados". Si bien el objetivo de este catálogo es presentar, de manera breve, el proyecto de arquitectura (diseńo) de las viviendas y las opiniones de las personas que las habitan, deja en evidencia la existencia de casos que salen de la "normalidad" o "regularidad". Imilan (2016) reflexionó sobre esta emergente característica de las políticas de vivienda social, develando la apertura de esta a demandas particulares en cuanto al diseño de los proyectos. Fuster (2015), por su parte, develó la existencia de un tratamiento diferenciado en viviendas para personas de origen étnico, quienes cuentan con instrumentos, modos de gestión, financiamiento, tipo de actores involucrados, entre otros, diferentes a los de otros grupos. Este tipo de casos deja en evidencia las brechas entre el funcionamiento "regular" y el funcionamiento "excepcional" de la política. 
Actualmente, existen investigaciones sobre ciertos casos por sus particularidades, destacándolos como "buenas prácticas" o "hitos" en la política de vivienda social. Estas investigaciones logran capturar las características de estos casos, describiendo su composición y procesos participativos. Es decir, son considerados una excepcionalidad, en la definición "positiva" del término. Sin embargo, no existe mayor reflexión sobre cómo estas experiencias son la expresión de un nuevo paradigma de la política de vivienda, que promueve la inversión social para impulsar procesos colectivos, pero únicos, que dependan de la capacidad de gestión de los habitantes y funcionarios, y no de los instrumentos de la política. Es un paradigma que estimula las alianzas público-privadas con otros actores no considerados dentro de sus procesos y que permite a los destinatarios de los proyectos gozar de beneficios especiales, si se cumple con las dos primeras condiciones (esto es, premia o bonifica la particularidad).

Estas lógicas excepcionales de la política consolidan su carácter individualizado y diferenciado, características basales de las lógicas de intervención empresariales. Estos atributos le otorgan un "estatus híbrido" a la política de vivienda social, el cual está definido por la mantención de las lógicas de subvención a la oferta y la competencia en el mercado del suelo y de la vivienda, la combinación de lógicas públicas y privadas (Blessing, 2012), la integración de nuevos actores privados y organizaciones sin fines de lucro, la diversidad de prácticas "no develadas" en la gestión pública, la preocupación por aumentar el estándar de construcción y localización, la formalización de los mecanismos de participación ciudadana y la producción de nuevas estratificaciones dentro de los mecanismos de focalización social regulares.

Los casos presentados son aparentemente poco comparables en su origen, objetivos, financiamiento, expresión, entre otros. Sin embargo, se pueden reconocer ciertos patrones o elementos comunes en ellos.

Primero, el carácter excepcional de los casos depende de la capacidad que tienen los distintos actores no considerados en la esencia "regular" de la política de vivienda, para articular redes y recursos complementarios.

Segundo, si bien los casos no fueron evaluados en términos técnicos, sus actores coinciden en que el estándar, tanto en calidad como en diseño, es superior al de la política "regular" de vivienda social.

Tercero, en los cuatro casos presentados coincide el interés que tienen los actores políticos para su emergencia; en tres de los cuatro, ocurre que este interés proviene de fuerzas vinculadas a partidos de la centro-derecha chilena.

Cuarto, se reafirma que uno de los elementos clave para avanzar hacia ciudades más equitativas es la localización de las viviendas en la geografía económica, laboral, educacional, de salud, de transporte, de equipamiento, y de lugares para el esparcimiento y para el ocio. En esta línea argumental, el análisis aporta evidencia a trabajos anteriores respecto de la dificultad para construir vivienda social en terrenos de alta plusvalía (Trivelli, 2011), provocando que el suelo se convierta en un objeto en disputa, situación en que los subsidios habitacionales vendrían a asumir el aumento histórico de sus precios, sacrificando la calidad de las viviendas (Castillo \& Forray, 2014). Los casos presentados reafirman estas hipótesis, puesto que la localización es resuelta por otros mecanismos externos al subsidio, dependientes de 
intereses políticos o particulares, permitiendo mayor estándar en las soluciones. Sin embargo, es preciso recalcar que los casos no "excepcionales" (vale decir, aquellos que tienen un carácter de "normalidad" o "regularidad") no cuentan con esta aparente "posibilidad” de disponer de suelo bien localizado. Esta dimensión es tensionante para la política, pues, por un lado, la excepcionalidad genera condiciones de hábitat digno que permiten ser ejemplos de replicabilidad; pero por otro, no resuelve los problemas estructurales de la política de vivienda que afectan a la mayoría de su población objetivo.

Quinto, el involucramiento de los organismos públicos en este tipo de proyectos demuestra que, si bien puede ser menos eficiente en términos de producción (en su mayoría son proyectos de baja escala), sí lo es en términos de calidad.

Sexto, si bien los casos son presentados como destacados, ellos muestran ciertas fisuras que pueden ser propias de procesos excepcionales, donde hay diversidad de actores involucrados que no necesariamente tienen expertise en la política de vivienda social.

Finalmente, en un séptimo punto, en las entrevistas algunos de los actores coinciden en la imposibilidad de replicabilidad de estos casos en otros contextos políticos y territoriales. Sin embargo, podemos observar cómo algunos se han transformado en experiencias piloto de nuevas líneas en los programas del Minvu.

A partir de lo anterior, se puede afirmar que es posible hablar de políticas de excepción en el contexto de la política de vivienda social chilena, la cual incorpora componentes de otros modelos de intervención excepcional, tales como: la discriminación positiva, que da prioridad o bonifica a ciertos grupos específicos de la sociedad; las políticas de focalización a grupos específicos o especialmente vulnerables; las políticas de reconocimiento de derechos; las políticas de urgencia, que otorgan libertades que en contextos regulares no existen, entre otras. Todos estos modelos (unos más institucionalizados que otros) plantean una intervención diferenciada por parte de la política social.

Por último, ciertamente estas políticas que suponen un trato preferencial producen gratificaciones materiales y simbólicas: materiales con relación a la localización y diseño de las viviendas, y simbólicas en cuanto a la percepción que sus habitantes y el entorno social y político tienen de ellas. No obstante, también es cierto que este tratamiento preferencial promueve desigualdades al interior de las mismas soluciones y "beneficiarios" de la política, produciendo una cierta elitización entre los actores implicados, pues establece preferencias de unos por sobre otros.

\section{Referencias bibliográficas}

Angelcos, N. \& Pérez, M. (2017). De la "desaparición" a la reemergencia: continuidades y rupturas del movimiento de pobladores en Chile. Latin American Research Review, 52(1), 94-109. http://doi.org/10.25222/larr.39

Aravena, L. (2011, 12 de agosto). Las casas-ruca, la nueva apuesta de Huechuraba. Plataforma Urbana. https://bit.ly/2x5RgQg 
Banco Mundial (1993). Vivienda: un entorno propicio para el mercado habitacional. Washington, D.C.: Banco Mundial.

Blanco, B. (2010, 25 de agosto). Construyen viviendas sociales adaptadas a costumbres mapuches. La Tercera. https://bit.ly/2xdONm7

Blessing, A. (2012). Magical or monstrous? Hybridity in social housing governance. Housing Studies, 27(2), 189-207. https://doi.org/10.1080/02673037.2012.649469

Borja, J. (2015). La vivienda popular, de la marginación a la ciudadanía. En A. Rodríguez, P. Rodríguez \& A. Sugranyes (eds.), Con subsidio, sin derecho. La situación del derecho a una vivienda adecuada en Chile (pp. 245-264). Santiago: Ediciones SUR. http://www. sitiosur.cl/r.php?id=941

Brandsen, T., Van de Donk, W. \& Putters, K. (2005). Griffins or chameleons? Hybridity as a permanent and inevitable characteristic of the third sector. International Journal of Public Administration, 28(9-10), 749-765. https://doi.org/10.1081/PAD-200067320

Brenner, N. \& Theodore, N. (2015). Neoliberalism and the urban condition. City, 9(1), 104107. https://doi.org/10.1080/13604810500092106

Building and Social Housing Fundation. (2016, 31 de octubre). Viviendas sociales resilientes. Finalista 2016, Chile: World Habitat Awards. https://bit.ly/2yjTppK

Castillo, M. \& Forray, R.(2014). La vivienda, un problema de acceso al suelo. ARQ, (86), 4857. https://dx.doi.org/10.4067/S0717-69962014000100007

Dardot, P. \& Laval, C. (2010). La nouvelle raison du monde. Essai sur la société néolibérale. París: La Découverte/Poche.

De Paula Faleiros, V. (2004). Las funciones de la política social en el capitalismo. En E. Borgianni \& C. Montaño (eds.), La política social hoy (pp. 43-70). San Pablo: Cortez Editora.

Espinoza, V. (1988). Para una historia de los pobres de la ciudad. Santiago: Ediciones SUR. [Libro escaneado formato PDF, en http://www.sitiosur.cl/r.php?id=249]

Foucault, M. (1976-1988). Dits et écrits II. París: Quatro Gallimard.

Franco, J. (2015, 2 de febrero). Neo cité, vivienda social en el centro de Santiago: por una ciudad inclusiva y equitativa. Plataforma Urbana. https://bit.ly/2Qt5W48

Fuster, X. (2015). (Re)conocimiento de la ciudad mapuche: etnicidad y construcción del hábitat en la Villa Bicentenario de Cerro Navia. Tesis para optar al grado de magíster en Hábitat Residencial, Facultad de Arquitectura y Urbanismo, Universidad de Chile, Santiago.

Fuster, X. \& Ayenao, M. (2016). Vivienda social para pueblos indígenas: preguntas a la política habitacional. En W. Imilan (ed.), Pueblos originarios y hábitat residencial urbano: diálogo sobre politicas habitacionales y pertinencia cultural en Chile (pp. 30-35). Santiago: Universidad de Chile / Corporación Nacional de Desarrollo Indígena (Conadi).

Garcés, M. (2002). Tomando su sitio. El movimiento de pobladores de Santiago 1979-1970. Santiago: LOM Ediciones.

Garretón, M. (2012). Neoliberalismo corregido y progresismo limitado. Los gobiernos de la Concertación en Chile. 1990-2010. Santiago: Arcis (Universidad de Arte y Ciencias Sociales) / Consejo Latinoamericano de Ciencias Sociales (Clacso).

Gaudichaud, F. (2015) Las fisuras del neoliberalismo chileno. Trabajo, crisis de la "democracia tutelada" y conflictos de clases. Santiago: Quimantú / Tiempo Robado Editoras.

Hamzaoui, M. (2002). Le travail social territorialisé. Bruselas: Éditions de l'Université de Bruxelles. 
Hidalgo, R. (1999). La vivienda social en Chile: la acción del Estado en un siglo de planes y programas. Scripta Nova. Revista Electrónica de Geografía y Ciencias Sociales, 45(1), 1-13. https://bit.ly/2NqGeeS

Hidalgo, R. (2002). Vivienda social y espacio urbano en Santiago de Chile: Una mirada retrospectiva a la acción del Estado en las primeras décadas del siglo xx. EURE, 28(83), 83-106. http://dx.doi.org/10.4067/S0250-71612002008300006

Hidalgo, R. (2005). La vivienda social en Chile y la construcción del espacio urbano en el Santiago del siglo XX. Santiago: Dirección de Bibliotecas, Archivos y Museos (Dibam).

Hidalgo, R., Paulsen, A. \& Santana, L. (2016). El neoliberalismo subsidiario y la búsqueda de justicia e igualdad en el acceso a la vivienda social: el caso de Santiago de Chile (19702015). Andamios, 13(32), 57-81. https://bit.ly/2Okl0zE

Ilustre Muncipalidad de San Joaquín. (2013, 18 de junio). Proyecto Pacifico Rivas I y II se encuentra en su fase administrativa final para dar inicio a obras de construcción. Red San Joaquín. https://bit.ly/2ND0f57

Ilustre Municipalidad de San Joaquín (2017). Ajuste metodológico y diagnóstico. Estudio: "Actualización Plan Regulador Comunal de San Joaquin". Santiago: Habiterra Consultores.

Imilan, W. (2016). Politicas y luchas por la vivienda en Chile: el camino neoliberal. Santiago: Contested Cities.

Imilan, W. (2017a). Luchas y demandas por la vivienda indígena urbana. Emergencia de conjuntos de vivienda subsidiada para población indígena urbana en Chile. AUS [Arquitectura / Urbanismo / Sustentabilidad], (21), 61-67. https://bit.ly/2x8aSDu

Imilan, W. (2017b). Demandas indígenas por vivienda en Santiago de Chile. En W. Imilan, J. Larenas, G. Carrasco \& S. Rivera (eds.), ¿Hacia dónde va la vivienda en Chile? Nuevos desafios en el hábitat residencial (pp. 41-52). Santiago: Instituto de la Vivienda, Universidad de Chile.

Maillet, A. (2015). Variedades de neoliberalismo. Innovación conceptual para el análisis del rol del Estado en los mercados. Revista de Estudios Políticos, (169), 109-136. https://doi. org/10.18042/cepc/rep.169.04

Ministerio de Vivienda y Urbanismo (Minvu), Chile (2012, 16 de octubre). Ministro Pérez inspecciona la reconstrucción de 534 viviendas en Dichato. Archivo histórico Minvu. https://bit.ly/2NdUn2E

Ministerio de Vivienda y Urbanismo (Minvu), Chile (2013). Normativa Técnica 007. Diseño estructural para edificaciones en áreas de riesgo de inundación por tsunami o seiche. Santiago: Minvu. https://bit.ly/2j2rQyY

Offe, C. (1990). Contradicciones en el Estado del Bienestar. Madrid: Alianza Universidad.

Pereira, P. (2004). La política social en el contexto de la seguridad social y del Welfare State: la particularidad de la asistencia social. En E. Borgianni \& C. Montaño (eds.), La política social hoy (pp. 149-165). San Pablo: Cortez Editora.

Pinson, G. \& Reigner, H. (2012). Différenciation et standardisation dans la(es) politique(s) urbaine(s). En A.-C. Douillet, A. Faure, C. Halpern \& J.-P. Leresche (dirs.), L'action publique locale dans tous ses états. Différenciation et standardisation (pp. 163-177). París: L'Harmattan.

Portal Inmobiliario (2011, 18 de octubre). Las casas mapuches en Huechuraba a dos meses de su entrega. Portal inmobiliario. https://bit.ly/2NaE7Q0 
Ravinet, P. \& Palier, B. (2015). 'Global es-tu là ?' Réflexions sur une catégorie analytique fantomatique. En L. Boussaguet, S. Jacquot \& P. Ravinet (dirs.), Une "French touch" dans l'analyse des politiques publiques? (pp. 27-56). París: Presses de Sciences Po.

Rodríguez, A. \& Sugranyes, A. (2005). Los con techo: un desafio para la politica de vivienda. Santiago: Ediciones SUR. http://www.sitiosur.cl/r.php?id=81

Rolnik, R. (2017). La guerra de los lugares. La colonización de la tierra y la vivienda en la era de las finanzas. Santiago: LOM Ediciones.

Saball, P. (2016). Presentación ministra. En Ministerio de Vivienda y Urbanismo, Obras urbanas y habitacionales con pertinencia indigena (pp. 6-7). Santiago: Ministerio de Vivienda y Urbanismo. https://bit.ly/2Myi9Bu

Sabatini, F. (2000). Reforma de los mercados de suelo en Santiago, Chile: efectos sobre los precios de la tierra y la segregación residencial. EURE, 26(77), 49-80. https://dx.doi. org/10.4067/S0250-71612000007700003

Trivelli, P. (2011). La propuesta de modificación del Plan Regulador Metropolitano de Santiago PRMS Ioo requiere una justificación más sólida. EURE, 37(111), 179-184. https:// dx.doi.org/10.4067/S0250-71612011000200009 